Vol 5. No 2. Agustus 2021

ISSN 2580-5029

\title{
Pengaruh Ketinggian Tempat Tumbuh Terhadap Kandungan Fitokimia dan Antioksidan Ekstrak Akar Sawi Langit (Vernonia cinerea L.)
}

\author{
Sri Lestari 1*, Riska Desi Aryani 1, Dian Palupi ${ }^{1}$ \\ ${ }^{1}$ Universitas Jenderal Soedirman, Banyumas, Indonesia \\ *lestari228@unsoed.ac.id
}

\section{ABSTRACT}

This study aims to determine the effect of altitude on the phytochemical and antioxidant content of sawi langit (Vernonia cinerea L.) root. Sawi langit is a herbaceous plant that has potential as a medicinal plant. This plant can thrive in the tropics. In this study, sawi langit were taken from three altitudes, namely <400 masl, 401-800 masl and >801 masl in the Banyumas, central Java. The sample used was sawi langit root which was extracted using 3 types of solvents (methanol, ethyl acetate and n-hexan). Phytochemical tests showed positive results of the content of flavonoid, alkaloids, tannins, terpenoids and saponins compounds in the extract of sawi langit root from the three altitude with differences effectiveness of each solvent. At an altitude of $<400$ masl and extraction using methanol resulted strong antioxidant activity with an $I C_{50}$ value $78.56 \pm 3.2 \mu \mathrm{g} / \mathrm{ml}$ compared to an altitude of 401-800 masl and >801 masl.

Keywords: Vernonia, altitude, phytochemical, antioxidant, medicinal plant

\begin{abstract}
ABSTRAK
Penelitian ini bertujuan untuk mengetahui pengaruh ketinggian tempat tumbuh terhadap kandungan fitokimia dan antioksidan akar sawi langit (Vernonia cinerea L.). Sawi langit merupakan tumbuhan herba yang memiliki potensi sebagai tanaman obat. Tumbuhan ini dapat tumbuh subur di daerah tropis. Pada penelitian ini sawi langit diambil dari tiga ketinggian tempat tumbuh yaitu $<400 \mathrm{mdpl}$, 401-800 $\mathrm{mdpl}$ dan $>801 \mathrm{mdpl}$ yang berada di daerah banyumas, jawa tengah. Sampel yang digunakan berupa akar sawi langit yang diekstrak menggunakan 3 jenis pelarut yaitu metanol, etil asetat dan n-heksan. Uji fitokimia menunjukkan hasil positif adanya kandungan senyawa flavonoid, alkaloid, tannin, terpenoid dan saponin pada ekstrak akar sawi langit dari ketiga ketinggian tempat tumbuh dengan perbedaan efektivitas masing-masing pelarut. Pada ketinggian tempat $<400 \mathrm{mdpl}$ dan ekstraksi akar sawi langit menggunakan metanol menghasilkan aktivitas antioksidan kategori kuat dengan nilai $\mathrm{IC}_{50} 78,56 \pm 3,2 \mu \mathrm{g} / \mathrm{ml}$ dibandingkan ketinggian 401-800 mdpl dan >801 mdpl.
\end{abstract}

Kata Kunci: Vernonia, altitude, fitokimia, antioksidan, tanaman obat

\section{PENDAHULUAN}

Sawi langit (Vernonia cinerea L.) merupakan tumbuhan herba tahunan yang tumbuh subur di daerah tropis seperti
Indonesia. Sawi langit merupakan salah satu jenis tumbuhan cosmopolitan yang dapat tumbuh pada berbagai ketinggian tempat baik dataran rendah maupun dataran tinggi. 
Indonesia sebagai negara tropis memiliki perbedaan kondisi lingkungan berdasarkan keberadaan tempat tersebut. Perbedaan ketinggian tempat menghasilkan iklim yang berbeda baik secara biotik maupun abiotik. Kondisi lingkungan yang dapat diamati dari perbedaan ketinggian tempat diantaranya adalah suhu, kelembaban, intensitas cahaya, intensitas curah hujan dan kecepatan angin (Ping et al, 2013). Kondisi lingkungan tersebut akan membentuk suatu sistem yang dapat berpengaruh pada tumbuhan yang tumbuh pada lingkungan tersebut. Kondisi lingkungan sangat berpengaruh pada proses fisiologis tumbuhan baik berupa metabolisme primer maupun sekunder. Metabolisme primer akan menghasilkan pertumbuhan yang dapat diamati dari morfologi tumbuhan tersebut sedangkan metabolisme sekunder dapat berupa mekanisme kimia yang terjadi dalam tubuh tumbuhan (Montesinos-Navarro et al, 2011).

Secara morfologi tumbuhan ini dapat tumbuh mencapai $100 \mathrm{~cm}$ dan diduga setiap bagian organ tumbuhan ini dapat dimanfaatkan sebagai bahan obat. Secara tradisional, tumbuhan ini dimanfaatkan oleh masyarakat untuk pengobatan, akan tetapi pemanfaatannya masih sangat rendah. Pada beberapa penelitian, tanaman ini dapat dimanfaatkan sebagai salah satu bahan untuk pengobatan, diantaranya bisul, demam, batuk, disentri, diuretic, selain itu tanaman ini juga memiliki aktifitas antimikroba, antiinflamasi serta antimalaria (Dagawal and Tarekar, 2017; Shelar et al, 2014; Haque et al, 2012).

Tumbuhan ini merupakan tumbuhan liar yang berpotensi sebagai tanaman obat. Hasil penelitian Laosim et al (2011), menunjukkan ekstrak n-heksan tumbuhan ini dapat mengatasi gangguan pencernaan dan imunomodulator sedangkan ekstrak metanol memiliki aktivitas antimikroba dan anti patogen. Ekstrak tumbuhan utuh dapat digunakan untuk mengobati gangguan ginjal, sakit perut dan eczema (Suresh et al, 2015). Hasil penelitian tersebut menunjukkan adanya potensi besar yang dimiliki oleh tumbuhan ini. Pengkajian dan penelitian jenis senyawa yang terkandung di dalam organ tumbuhan ini khususnya akar dapat menjadi dasar ilmiah untuk pemanfaatan dalam skala yang lebih besar. Akar merupakan salah satu organ utama pada tumbuhan yang memiliki fungsi diantaranya sebagai penyerap nutrisi serta sebagai penyimpan hasil metabolisme tumbuhan. Dengan fungsi tersebut dimungkinkan akar mengandung beberapa jenis senyawa hasil metabolisme sekunder yang bermanfaat untuk bahan obat.

Penelitian ini bertujuan untuk mengetahui pengaruh ketinggian tempat tumbuh terhadap kandungan metabolit sekunder dan aktivitas antioksidan serta mengetahui pelarut yang sesuai untuk mengisolasi senyawa metabolit sekunder pada akar sawi langit. 


\section{METODE}

Sampel dikoleksi secara eksplorasi di kabupaten Banyumas dan sekitarnya pada kisaran ketinggian < 400 mdpl (Banyumas dan Purwokerto), 401-800 mdpl (Cilongok dan Sumbang) dan >801 mdpl (Baturaden dan Purbalingga). Pengambilan sampel akar sawi langit dilakukan secara acak terpilih. Selanjutnya akar dikering anginkan pada suhu ruang selama kurang lebih 10 hari. Akar yang telah kering sempurna dihaluskan menggunakan mortar kemudian 50 gram akar kering diekstraksi menggunakan metanol, etil asetat dan n-heksan. Masing-masing ekstraksi dilakukan selama 3 hari, dengan penyaringan setiap hari. Hasil ekstraksi yang telah disaring diuapkan menggunakan rotary evaporator.

\section{Uji Fitokimia}

Skrining Fitokimia dilakukan untuk mengetahui adanya kandungan senyawa dalam akar sawi langit berupa flavonoid, alkaloid, tannin, terpenoid dan saponin. Identifiksi masing-masing jenis senyawa dilakukan menggunakan metode pereaksi kimia dengan modifikasi dan diamati dari reaksi perubahan warna yang terjadi. Identifikasi flavonoid dilakukan menggunakan pereaksi Willstater dan dinyatakan positif mengandung flavonoid apabila terjadi perubahan warna larutan menjadi jingga, merah, hijau atau kuning. Identifikasi alkaloid dilakukan dengan pereaksi Mayer dan kloroform dan dinyatakan positif jika terdapat endapan. Identifikasi tannin menggunakan $\mathrm{FeCl}_{3}$ 10\%. Identifikasi terpenoid menggunakan pereaksi Liberman Burchard dan dinyatakan positif jika jika terjadi perubahan warna menjadi merah atau kuning dan saponin diidentifikasi menggunakan aquades kemudian dikocok selama 5 menit dan dinyatakan positif jika terbentuk busa dan selama 30 detik tidak menghilang (Harborne, 1987).

\section{Uji Antioksidan}

Uji antioksidan dilakukan dengan metode DPPH (2,2-difenil-1- pikrilhidrazil). Serbuk DPPH $\quad(0,2 \quad \mathrm{mM})$ ditimbang 7,88 gram kemudian dilarutkan dalam $100 \mathrm{~mL}$ metanol. Sampel ekstraksi dibuat dalam konsentrasi 1,075; 6,25; 12,5; 15; 25; 50; 75;100; 150 dan 200 ppm. Sampel dengan masing-masing konsentrasi tersebut diambil sebanyak $2 \mathrm{ml}$, ditambah $2 \mathrm{ml}$ DPPH 0,2 mM kemudian dihomogenkan. Diinkubasi suhu ruang kondisi gelap selama 30 menit kemudia diukur absorbansi pada panjang gelombang 517 (Prieto, 2012). Aktivitas antioksidan dihitung dengan rumus berikut untuk membuat nilai regresi penentuan $\mathrm{IC}_{50}$ :

$$
\% \text { aktivitas }=\frac{\text { OD blanko }- \text { OD sampel }}{\text { OD blanko }} \times 100
$$

Tabel 1. Kriteria aktivitas antioksidan dari nilai IC 50

\begin{tabular}{ll}
\hline Kriteria & Nilai IC $_{\mathbf{5 0}}$ \\
\hline Sangat kuat & $<50$ \\
Kuat & $50-100$ \\
Sedang & $101-250$ \\
Lemah & $251-500$ \\
Tidak memiliki antioksidan & $>500$ \\
\hline
\end{tabular}




\section{Analisis data}

Data kualitatif yang diperoleh dianalisis secara deskriptif sedangkan data kuantitatif dianalisis menggunakan anova satu arah. Apabila terdapat pengaruh signifikan dilanjutkan dengan DMRT (Duncan's Multiple Range Test) pada taraf kesalahan 5\%.

\section{HASIL DAN PEMBAHASAN}

Pada penelitian ini digunakan tiga jenis pelarut dengan tingkat kepolaran berbeda untuk mengetahui efektifitas pelarut dalam selektifitas dan mengekstraksi senyawa yang terkandung dalam akar sawi langit. Pelarut yang digunakan adalah methanol, etil asetat dan n-heksan. Metanol merupakan jenis pelarut yang bersifat polar atau mudah larut dengan air. Etil asetat memiliki sifat semi polar sedangkan n-heksan memiliki sifat non polar. Sifat polaritas setiap jenis pelarut tersebut akan berpengaruh terhadap selektifitas jenis senyawa yang akan terekstrak. Kelarutan senyawa memiliki prinsip polaritas pelarut akan melarutkan senyawa dengan polaritas yang sama. Senyawa kimia dalam organ tumbuhan memiliki kepolaran yang berbeda tergantung dengan letak gugus hidroksil dan susunan setiap unsur kimianya (Harborne, 1987). Perbedaan sifat kepolaran dari pelarut akan memungkinkan perbedaan senyawa hasil dari ekstraksi, seperti halnya pada penelitian ini menunjukkan pelarut methanol dapat menghasilkan senyawa fitokimia dan antioksidan yang lebih tinggi dibandingkan etil asetat dan n-heksan.

Pengaruh ketinggian tempat tumbuh terhadap kandungan fitokimia ekstrak akar sawi langit

Sawi langit merupakan tumbuhan semusim dengan habitus herba dan jenis tumbuhan dikotil dengan akar tunggang (Gambar 1). Berdasarkan hasil skrining fitokimia yang telah dilakukan didapatkan hasil bahwa akar sawi langit dinyatakan positif mengandung beberapa jenis senyawa metabolit sekunder yang berkhasiat sebagai obat (Tabel 2). Berdasarkan skrining tannin akar sawi langit dinyatakan positif dari sampel ketinggian <400 mdpl dan >801 mdpl dengan pelarut ekstraksi metanol. Sedangkan pada ketinggian 401-800 mdpl dan pelarut etil asetat dan $\mathrm{n}$-heksan tidak terdeteksi adanya senyawa tannin.

Skrining alkaloid dari ketiga ketinggian tempat tumbuh menunjukkan hasil positif pada akar yang diekstrak menggunakan metanol sedangkan akar yang diekstrak menggunakan etil asetat dan n-heksan tidak terdeteksi adanya senyawa alkaloid. Pada skrining flavonoid menunjukkan hasil positif dari ketiga ketinggian tempat tumbuh dan ketiga jenis pelarut. Skrining terpenoid ekstrak akar pada ketinggian < 400 mdpl menunjukkan hasil positif dari ketiga jenis pelarut yang digunakan sedangkan pada ketinggian 401-800 mdpl pelarut etil asetat dan n-heksan menunjukkan hasil positif sedangkan pelarut metanol menunjukkan 
Biotropic Tahun 2021, Vol.5 (No. 2): 84 - 93

hasil negatif dan pada ketinggian $>801 \mathrm{mdpl}$ terpenoid terdeteksi positif pada pelarut metanol dan n-heksan sedangkan pada pelarut etil asetat tidak terdeteksi senyawa tersebut. Skrining saponi dari ketinggian tempat tumbuh menunjukkan hasil yang sama yaitu terdeteksi positif pada ekstrak akar dengan pelarut metanol dan n-heksan sedangkan pada pelarut etil asetat tidak terdeteksi adanya saponin.

Berdasarkan hasil skrining fitokimia tersebut menunjukkan bahwa secara keseluruhan akar sawi langit mengandung senyawa metabolit sekunder yaitu tannin, alkaloid, flavonoid, terpenoid dan saponin. Dari analisis ketiga tempat tumbuh menunjukkan bahwa sawi langit yang tumbuh pada ketinggian $<400 \mathrm{mdpl}$ memperoleh hasil deteksi senyawa terbanyak dibandingkan dengan ketinggian >801 mdpl, dan hasil terendah pada ketinggian 401-800 mdpl. Hasil tersebut menunjukkan bahwa metabolit sekunder akar sawi langit dapat dihasilkan secara optimal pada ketinggian tempat tumbuh $<400 \mathrm{mdpl}$.

Pada ketinggian <400 mdpl tergolong dalam kategori dataran rendah, dengan jenis tanah secara umum merupakan alluvial, latosol dan gramosol. Jenis-jenis tanah tersebut merupakan tanah yang memiliki tingkat kesuburan yang relatif baik (Purwanto, 2020). Kondisi lingkungan berperan penting untuk pertumbuhan dan perkembangan tumbuhan. Perbedaan ketinggian tempat dapat menghasilkan perbedaan kondisi lingkungan yang signifikan. Ketinggian tempat dapat menghasilkan temperatur, kelembapan, intensitas cahaya, curah hujan dan kandungan nutrisi dalam tanah yang berbeda (Ping et al, 2013). Dataran rendah memiliki intensitas cahaya dengan suhu lingkungan yang lebih tinggi dibandingkan dataran sedang dan tinggi. Cahaya matahari sangat berpengaruh pada proses fotosintesis pada tumbuhan yang berkorelasi dengan kandungan metabolit baik primer maupun sekunder (Yuliani et al, 2019).

Intensitas cahaya yang cukup dapat meningkatkan efisiensi sintesis senyawa organic pada akar sawi langit melalui proses fotosintesis (Sandi et al, 2019). Hal tersebut berkorelasi dengan penelitian ini karena dari hasil skrining fitokimia menunjukkan ekstrak akar sawi langit yang tumbuh pada dataran rendah menghasilkan senyawa yang paling banyak. Dengan pelarut metanol mampu mengikat senyawa lebih baik dibandingkan etil asetat dan n-heksan (Begasshaw et al, 2017). Metanol merupakan senyawa polar yang mampu mampu larut dan melarutkan air serta senyawa polar lainnya. Selain itu metanol adalah salah satu jenis pelarut yang banyak digunakan dalam ekstraksi tumbuhan untuk mengisolasi senyawa metabolit sekunder pada tumbuhan. 


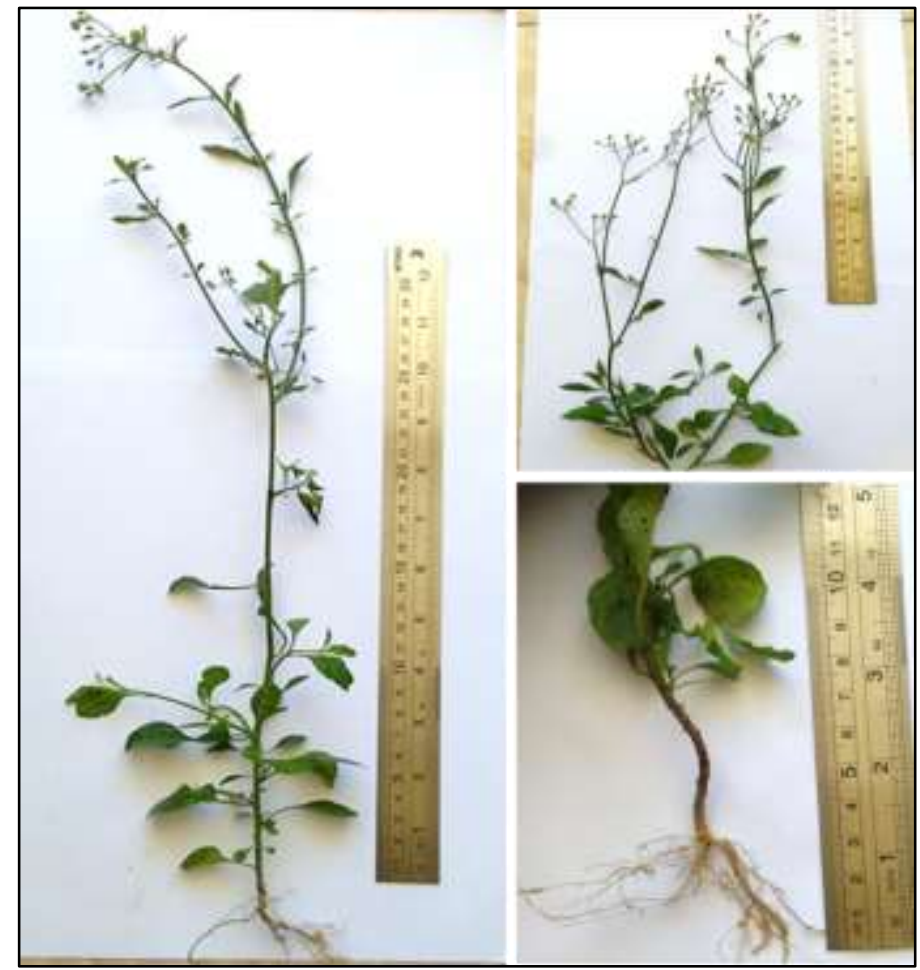

Gambar 1. Morfologi sawi langit (Vernonia cinerea L.)

Tabel 2. Pengaruh ketinggian tempat tumbuh terhadap hasil skrining fitokimia ekstrak akar sawi langit.

\begin{tabular}{|c|c|c|c|c|c|c|}
\hline Ketinggian & Pelarut & Tanin & Alkaloid & Flavonoid & Terpenoid & Saponin \\
\hline \multirow{3}{*}{$\begin{array}{l}<400 \text { mdpl } \\
\text { (Rendah) }\end{array}$} & Metanol & + & + & + & + & - \\
\hline & Etil Asetat & - & - & + & + & - \\
\hline & N-Heksan & - & - & + & + & + \\
\hline \multirow{3}{*}{$\begin{array}{l}\text { 401-800 mdpl } \\
\text { (Sedang) }\end{array}$} & Metanol & - & + & + & - & - \\
\hline & Etil Asetat & - & - & + & + & - \\
\hline & N-Heksan & - & - & + & + & + \\
\hline \multirow{3}{*}{$\begin{array}{l}>\mathbf{8 0 1} \text { mdpl } \\
\text { (Tinggi) }\end{array}$} & Metanol & + & + & + & - & + \\
\hline & Etil Asetat & - & - & + & - & - \\
\hline & N-Heksan & - & - & + & + & + \\
\hline
\end{tabular}

Pengaruh ketinggian tempat tumbuh terhadap kandungan antioksidan ekstrak akar sawi langit

Uji aktivitas antioksidan dilakukan dengan metode DPPH kemudian mengukur absorbansi menggunakan spektrofotometri UV-Vis pada panjang gelombang 517 untuk memperoleh nilai IC50. Berdasarkan hasil analisis statistik menunjukkan adanya pengaruh ketinggian tempat tumbuh terhadap aktivitas antioksidan ekstrak akar sawi langit. Hasil uji aktivitas antioksidan menunjukkan bahwa akar sawi langit yang tumbuh pada ketinggian <400 mdpl dan >801 mdpl dengan pelarut methanol menghasilkan aktivitas antioksidan pada kategori kuat dengan nilai IC50 secara berurutan yaitu 78,56 $\pm 3,2$ dan $86,71 \pm 2,6 \mu \mathrm{g} / \mathrm{ml}$, sedangkan pada ketinggian 
401-800 mdpl memiliki kategori sedang. Pada ekstraksi akar sawi langit yang menggunakan pelarut etil asetat dan n-heksan dari ketiga ketinggian tempat tumbuh memiliki aktivitas antioksidan pada kategori sedang (Tabel 3).

Aktivitas antioksidan yang dihasilkan memiliki kategori kuat pada ekstraksi dengan metanol dibanding etil asetat dan n-heksan. Dari hasil tersebut dapat diketahui bahwa metanol mampu mengekstrak senyawa antioksidan dari akar sawi langit dengan lebih kuat sehingga diperoleh hasil aktivitas antioksidan yang lebih tinggi secara kuantitatif. Metanol merupakan senyawa yang umum digunakan sebagai pelarut pada ekstraksi tumbuhan khususnya untuk deteksi aktivitas antioksidan. Hal ini dikarenakan metanol merupakan pelarut yang bersifat polar yang mampu melarutkan senyawa polar lainnya dengan baik. Dari hasil analisis tersebut dimungkinkan kandungan senyawa aktif dari antioksidan memiliki sifat polar sehingga pelarut dengan polaritas yang sama mampu mengekstrak dengan lebih optimal.

Dari hasil analisis tersebut menunjukkan bahwa ketinggian tempat tumbuh $<400 \mathrm{mdpl}$ dan >801 mdpl dengan pelarut metanol dapat menghasilkan aktivitas antioksidan lebih kuat dibanding kan dengan ketinggian 401-800 mdpl. Kondisi lingkungan pada dataran rendah dan tinggi mampu mendorong terbentuknya metabolit sekunder lebih tinggi dibandingkan ketinggian sedang. Keberadaan senyawa antioksidan dalam organ tumbuhan merupakan salah satu produk metabolisme tumbuhan. Ketinggian tempat memberikan pengaruh paling besar pada metabolisme tumbuhan berkaitan dengan ketersedianan cahaya matahari, suhu lingkungan dan nutrisi (Montesinos-Navarro et al, 2011).

Dataran rendah lokasi pengambilan sampel memiliki suhu rata-rata 27-310C dengan kelembaban 75 - $85 \%$ dan intensitas cahaya pada kategori sedang sampai tinggi. Faktor-faktor tersebut merupakan faktor abiotik yang membentuk suatu kondisi pada lingkungan. Faktor tersebut berpengaruh secara signifikan terhadap pertumbuhan dan perkembangan tumbuhan. Pada penelitian ini dataran rendah mampu menciptakan kondisi yang optimal untuk proses produksi senyawa fitokimia dan antioksidan sawi langit khususnya organ akar. Dataran rendah disebut juga sebagai dataran aluvial yang secara umum memiliki kondisi tanah subur dengan ketersediaan air cukup. Dataran rendah memiliki intensitas cahaya dan suhu udara yang cukup tinggi dengan curah hujan dan kelembaban yang rendah. Sedangkan dataran tinggi memiliki intensitas cahaya dan suhu rendah dengan curah hujan dan kelembaban tinggi (Puspitasari et al, 2013). Perbedaan suhu dan kelembaban pada lingkungan sangat berpengaruh pada proses metabolisme tumbuhan yang berkaitan dengan reaksi enzimatis sedangkan intensitas cahaya berpengaruh pada laju fotosintesis, transpirasi dan respirasi tumbuhan. Mekanisme tersebut akan berpengaruh pada produksi metabolit baik primer maupun 
metabolit sekunder tumbuhan (Yuliani et al, 2015). Adanya ketidaksesuaian kondisi lingkungan dapat mendorong tanaman untuk beradaptasi dengan cara memproduksi metabolisme sekunder lebih tinggi dibandingkan metabolisme primer (Fukui et al, 2017).

Dari hasil penelitian ini dapat diketahui bahwa dataran rendah dan tinggi mampu menghasilkan senyawa antioksidan yang kuat pada akar sawi langit. Hal tersebut menandakan dataran rendah dan dataran tinggi mampu mendorong proses metabolisme sawi langit untuk memproduksi metabolit sekunder yang lebih tinggi. Ketinggian tempat berkaitan secara langsung dan tidak langsung dengan iklim suatu tempat. Ketinggian tempat yang berkaitan langsung dengan iklim adalah suhu, intensitas cahaya matahari dan kelembaban (Kofidis and Bosabalidis, 2008). Pada dataran rendah memiliki intensitas cahaya yang tinggi sehingga tumbuhan dataran rendah dapat melakukan metabolisme secara optimal (Yoana, 2012). Sedangkan pada dataran tinggi memiliki kondisi lingkungan yang lebih ekstrim, hal ini menjadi salah satu faktor pemicu peningkatan metabolisme sekunder pada tumbuhan untuk melakukan adaptasi agar dapat bertahan hidup (MontesinosNavarro et al, 2011).

Tabel 3. Pengaruh ketinggian tempat tumbuh terhadap aktivitas antioksidan ekstrak akar sawi langit

\begin{tabular}{llcc}
\hline Ketinggian & Pelarut & $\begin{array}{c}\text { Aktivitas Antioksidan } \\
\left(\mathrm{IC}_{50} \pm \mathrm{SD} \boldsymbol{\mu g} / \mathbf{m l}\right)\end{array}$ & Kriteria \\
\hline \multirow{3}{*}{$<\mathbf{4 0 0}$ mdpl (Rendah) } & Metanol & $78,56 \pm 3,2^{\mathrm{a}}$ & Kuat \\
& Etil Asetat & $127,51 \pm 3,9^{\mathrm{c}}$ & Sedang \\
& N-Heksan & $113,64 \pm 4,5^{\mathrm{b}}$ & Sedang \\
\hline \multirow{3}{*}{$\mathbf{4 0 1 - 8 0 0 ~ m d p l ~ ( S e d a n g )}$} & Metanol & $121,61 \pm 4,1^{\mathrm{c}}$ & Sedang \\
& Etil Asetat & $161,85 \pm 2,7^{\mathrm{e}}$ & Sedang \\
& N-Heksan & $142,56 \pm 5,1^{\mathrm{d}}$ & Sedang \\
\hline \multirow{3}{*}{$\mathbf{8 0 1}$ mdpl (Tinggi) } & Metanol & $86,71 \pm 2,6^{\mathrm{a}}$ & Kuat \\
& Etil Asetat & $170,35 \pm 4,3^{\mathrm{e}}$ & Sedang \\
& N-Heksan & $125,73 \pm 4,8^{\mathrm{c}}$ & Sedang \\
\hline
\end{tabular}

Keterangan: Angka yang didampingi oleh huruf sama pada kolom yang bersesuaian tidak berbeda nyata pada uji DMRT $\alpha: 0.05$

\section{KESIMPULAN}

Ketinggian tempat tumbuh memberikan pengaruh terhadap kandungan fitokimia dan antioksidan akar sawi langit. Aktivitas antioksidan tertinggi diperoleh dari ketinggian < 400 mdpl dengan nilai IC50 78,56 $\pm \quad 3,2 \mu \mathrm{g} / \mathrm{ml}$ termasuk kategori kuat.
Ketinggian tempat $<400 \mathrm{mdpl}$ dapat menghasilkan kondisi lingkungan yang optimal untuk produksi metabolit sekunder pada akar sawi langit dengan pelarut ekstraksi metanol. 


\section{UCAPAN TERIMA KASIH}

Ucapan terima disampaikan kepada Lembaga Penelitian dan Pengabdian kepada Masyarakat (LPPM) Universitas Jenderal Soedirman atas pendanaan BLU tahun anggaran 2021 yang telah diberikan untuk pelaksanaan penelitian serta semua pihak yang telah membantu dalam penelitian.

\section{DAFTAR PUSTAKA}

Begashaw, B., Mishra, B., Tsegaw, A., and Shewamene, Z. 2017. Methanol leaves extract Hibiscus micranthus Linn exhibited antibacterial and wound healing activities. BMC Complementary and Alternative Medicine. 17(337): 1 11.

Dagawal, M., and Tarekar, D. 2017. Pharmacognostic studies of Vernonia cinerea (L.) Leaves - An antismoking plant. World Journal Pharm. Res. 6(1): 875 - 882 .

Fukui, S., Ishigooka, Y., Kuwagata, T., Kondo, M. and Hasegawa, T. 2017. Taking account of water temperature effects on phenology improves the estimation of rice heading dates: Evidence from 758 field observations across Japan. Journal Agric. Meteorol. 73(3) :84-91.

Harborne, JB. 1987. Metode Fitokimia : Penuntun cara modern menganalisa tumbuhan. Terbitan Kedua. Terjemahan Kosasih Padmawinata dan Iwang Soediro. ITB, Bandung.

Haque, AM., Hassan, MM., Das, A., Begum, B., Ali, YM., and Morshed, H. 2012. Phytochemical investigation of Vernonia cinerea (family: Asteraceae). Journal Appl. Pharm. Sci. 2(6): 79 - 83.

Kofidis, G. and Bosabalidis, AM. 2008. Effect of altitude and season on glandular hairs and leaf structural traits of Nepeta nuda L. Botanical studies. 49: 363 - 372.
Laosim, T., Chuchawankul, L., and Tencomnao, T. 2011. Immunomodulatory effect of hexane extract of Vernonia cinerea Less. trunk on human peripheral blood mononuclear cells. Journal Chem. Pharm. 3(4): 188 - 195.

Montesinos-Navarro, AJ., Wig, FX., Pico, and Tonsor, SJ. 2011. Arabidopsis thaliana populations show clinal variation in a climatic gradient associated with altitude. New Phytologist. 189: 282 294.

Ping, C., Michaelson, GJ., Stiles, CA., and González, G. 2013. Soil characteristics, carbon stores, and nutrient distribution in eight forest types along an elevation gradient, eastern Puerto Rico. Ecology Bulletine. 54: 67 - 86.

Prieto, JM. 2012. Procedure: Preparation of DPPH Radical, and antioxidant scavenging assay. Didownload pada 2018.

https://www.researchgate.net/profile/ Jose-Prieto-

10/post/Can anyone explain the DPP

$\mathrm{H}$ method for antioxidant activity in $\mathrm{d}$ etails/attachment/59d61efac49f47807 2e9772d/AS\%3A271744332435456\% 401441800305338/download/Prieto+ DPPH+protocol.pdf

Purwanto, A. 2020. Daerah Provinsi Jawa Tengah. Didownload pada Agustus 2020.

https://kompaspedia.kompas.id/baca/ profil/daerah/provinsi-jawa-tengah

Puspitasari, N., Santoso TI., and Mawardi, S. 2013. Sebaran Tingkat Kesuburan Tanah pada Perkebunan Rakyat Kopi Arabika di Dataran Tinggi Ijen-Raung Menurut Ketinggian Tempat dan Tanaman Penaung. Pelita Perkebunan. 29(2): 93-107.

Sandi, A., Sangadji, MN., and Samudin, S. 2019. Morfologi dan anatomi tanaman Kelor (Moringa oleifera L.) pada berbagai ketinggian tempat tumbuh. $e-J$. Agrotekbis. 7(1): 28 - 36. 
Shelar, D., Tikole, S., and Kakade, T. 2014. Vernonia cinerea: A Review. Journal Curr. Pharma Res. 4(3): 1194 - 1200.

Suresh, SN., Varsha, V., and Prejeena, V. 2015. Phytochemical screening of Vernonia cinerea leaf extracts. International Journal Med. Pharm. Res. 3(6): 1242 1245.

Yoana, P. 2012. The effect of light intensity on the stomatal density of lavender, Lavandula angustifolia. Young Scientists Journal. 12: 89 - 93.

Yuliani, Soemarno, Yanuwiadi, B., and Leksono, AS. 2015. The relationship between habitat altitude, enviromental factors and morphological characteristics of Pluchea indica, Ageratum conyzoides and Elephantopus scaber. OnLine Journal of Biological Sciences. 15(3): $143-151$. 